\title{
A RESPONSABILIDADE SOCIAL DAS EMPRESAS E SEUS EFEITOS NO COMPORTAMENTO DO CONSUMIDOR: UM ESTUDO QUALITATIVO
}

\author{
Renata Céli Moreira da Silva \\ Doutoranda em Administração de Empresas Pontifícia Universidade Católica do Rio de Janeiro - PUC \\ renata.celi@gmail.com \\ Marie Agnes Chauvel \\ Doutora em Administração pela Universidade Federal do Rio de Janeiro - UFRJ \\ Professora da Universidade Federal de São João Del-Rei - UFSJ \\ mariechauvel@gmail.com
}

\section{RESUMO}

Esse estudo teve o objetivo de investigar os efeitos da Responsabilidade Social Corporativa (RSC) sobre o comportamento do consumidor. Para isso, optou-se por um estudo qualitativo, em que foram feitas entrevistas em profundidade com dez consumidores, que eram profissionais da engenharia, todos empregados e responsáveis pelo próprio sustento. Os resultados apontaram que os entrevistados consideram este tema importante, porém, têm visões heterogêneas do que seja RSC. Se por um lado, eles não se lembraram de já ter beneficiado uma empresa socialmente responsável, comprando seus produtos, e alegaram que os motivos foram: falta de informação, pressa, falta de um selo que garantisse a RSC e o fato de os atributos preço e qualidade serem mais relevantes para suas decisões de compra, por outro, alguns entrevistados disseram já ter "punido" empresas irresponsáveis, deixando de comprar seus produtos. Os consumidores entrevistados foram unânimes quanto à necessidade de informação mais facilmente acessível para o comprador (como os selos em produtos), já que eles destacaram que não querem correr atrás da informação, e que, por isso, ela precisa estar disponível. Além disso, eles se mostraram céticos em relação às práticas de RSC. Esses resultados sugerem que uma maior transparência, por meio da divulgação das informações ou até a existência de um selo padrão que garanta que o produto é de origem socialmente responsável, poderia reduzir o ceticismo e, ao mesmo tempo, incentivar empresas e consumidores a aderir à RSC.

Palavras-chave: Brasil; Consumidor; Responsabilidade social corporativa.

\section{Corporate Social Responsibility and its Effects on Consumer Behavior: A Qualitative Study.}

\begin{abstract}
This study investigates the effects of Corporate Social Responsibility (CSR) on consumer behavior. We chose to do a qualitative study, and performed detailed interviews with ten self-supporting consumers who currently work as engineers. The results show that the interviewees think this subject is important, but that they have differing views on what CSR means. The interviewees did not recall having bought from socially responsible companies, and justified this through a lack of information from companies, their own haste, the absence of a certification process that guarantees CSR, and the relevance of price and quality to their decisions. Some interviewees confessed to having "punished" irresponsible companies by not buying their products. All of the consumers we interviewed pointed to the need for more easily accessed information (through a certification process for the products). Since they do not want to search for the information, it is important that it be visibly available. Conversely, they seemed to be skeptical about CSR practices. These results show that more transparency when informing people, or even the creation of a unified certification process that guarantees that the product is of socially responsible origin, could reduce skepticism and encourage companies and consumers to join the CSR trend.
\end{abstract}

Keywords: Corporative Social Responsibility, Consumer, Brazil.

Revista de Gestão Social e Ambiental - RGSA, São Paulo, v. 5, n. 2, p. 172-186, mai./ago. 2011. 


\section{INTRODUÇÃO}

Recentemente, tanto o meio empresarial quanto o meio acadêmico têm debatido bastante sobre o tema Responsabilidade Social Corporativa (RSC). Além disso, esse assunto tem estado na pauta dos mais diversos meios de comunicação, tais como revistas, jornais, programas de televisão, artigos e em seminários.

Pode-se dizer, então, que existe uma pressão, em âmbito mundial, para que as empresas sejam socialmente responsáveis (Marquis, Glynn \& Davis, 2007). Os consumidores têm seu papel nessa pressão, pois eles estão mais atentos às práticas das empresas (Kotler \& Armstrong, 1998). Muitos passam a comprar produtos de empresas que praticam a RSC, logo a RSC pode afetar as atitudes e crenças dos consumidores em relação aos produtos e serviços de determinada empresa (Mohr, Webb \& Harris, 2001).

Por conseguinte, diversas empresas estão adotando a RSC como uma prática nos seus negócios (Ventura, 2003), certificando que seus produtos são corretos (Vlosky, Ozanne \& Fontenot, 1999), publicando relatórios sociais (Fortanier \& Kolk, 2007), entre outras práticas.

Várias pesquisas têm sido feitas, sob o ponto de vista do consumidor, em relação a essas práticas (Sen \& Bhattacharya, 2001). Essas pesquisas procuram verificar se o comportamento socialmente responsável das empresas pode afetar o comportamento de compra. Há também estudos que procuram investigar se o comportamento socialmente irresponsável das empresas - os escândalos corporativos - pode gerar uma intenção de compra negativa (D'Angelo, 2003) e se os consumidores acreditam na RSC das empresas ou possuem uma postura cética em relação à RSC.

No Brasil, várias estudos (Motta \& Rossi, 2003; Castro, Siqueira \& Kubrusly, 2007; Serpa $\&$ Fourneau, 2007) revelam uma atitude positiva em relação à compra socialmente responsável, que parece não ser colocada em prática pelos consumidores. Diante disso, optou-se, neste estudo, por uma abordagem qualitativa. Buscou-se, com essa abordagem, obter um melhor entendimento do comportamento dos consumidores em relação às práticas socialmente responsáveis e irresponsáveis das empresas e investigar se os consumidores acreditam na honestidade das empresas em suas práticas de RSC. Este artigo possui a seguinte estrutura: neste item é apresentada a introdução. Em seguida, faz-se uma revisão da literatura, englobando a RSC e os resultados de estudos anteriores sobre RSC e comportamento do consumidor. No item seguinte, é feita uma descrição da metodologia de pesquisa e, logo após, são mostradas as análises dos resultados. Finalmente, são elaboradas as considerações finais.

\section{REVISÃO BIBLIOGRÁFICA}

\subsection{A Responsabilidade Social Corporativa (RSC)}

Atualmente, há muitas definições de RSC e, por isso, alguns autores afirmam que se trata de um conceito em construção (Ashley, 2002). Carroll (1991) definiu a RSC por meio de um modelo, chamado de "pirâmide da RSC", que engloba quatro dimensões: econômica, legal, ética e filantrópica. De acordo com Enderle e Tavis (1998), a RSC possui as dimensões econômica, ambiental e social. Eles também sublinham que a organização se relaciona com diversos públicos, a quem se aplica o conceito de RSC, os chamados stakeholders - funcionários, fornecedores, comunidade e grupos ambientais (Maignan, Ferrell \& Ferrell, 2005).

Para Mohr et al. (2001), a RSC diz respeito ao comprometimento da empresa em reduzir os impactos negativos e aumentar os impactos positivos para a sociedade. Maignan e Ferrell (2004) consideram que a RSC envolve múltiplas abordagens. São elas: obrigação social (linhas de ação coerentes com a missão e valores da empresa), obrigação para com os stakeholders (aqueles que estão direta ou indiretamente ligados à empresa), ética (ações movidas pela ética) e processo gerencial (gerenciamento necessário para o negócio). 
McWilliams e Siegel (2001), ao definirem a RSC, falam que as empresas devem tratar as decisões de RSC como elas tratam as outras decisões de investimento. E definem o termo como sendo as ações sociais, que vão além dos interesses da organização e do que é exigido pela lei.

De acordo com Ashley (2002), a RSC envolve o apoio ao desenvolvimento da comunidade em que a empresa atua, a preservação do meio ambiente, o investimento no bem-estar dos funcionários, o estabelecimento de uma comunicação transparente, o desenvolvimento de uma sinergia com os parceiros, a satisfação dos seus clientes e consumidores e a maximização dos lucros para os acionistas.

\subsection{A responsabilidade social segundo a ótica do consumidor}

Há vários estudos que investigam o comportamento dos consumidores em relação às práticas socialmente responsáveis das empresas, sendo a maioria, quantitativos. Neste item, são apresentados os resultados de pesquisas realizadas no Brasil que estudam o comportamento do consumidor e a RSC. A Figura 1 apresenta uma síntese dos resultados obtidos em pesquisas brasileiras sobre a RSC, segundo a ótica do consumidor.

\begin{tabular}{|c|c|}
\hline Resultados de pesquisas anteriores & Autores \\
\hline $\begin{array}{l}\text { Consumidor ainda não procura comprar produtos } \\
\text { de empresas éticas e/ou socialmente responsáveis }\end{array}$ & $\begin{array}{c}\text { Instituto Ethos (2002); Motta e Rossi } \\
\text { (2003); Castro et al. (2007); Serpa e } \\
\text { Fourneau (2007); Silva e Bertrand (2009) }\end{array}$ \\
\hline $\begin{array}{c}\text { Consumidor possui atitudes positivas em relação } \\
\text { aos produtos de empresas socialmente } \\
\text { responsáveis }\end{array}$ & $\begin{array}{l}\text { Motta e Rossi (2003); Castro et al. (2007); } \\
\text { Serpa e Fourneau (2007); Silva e Bertrand } \\
\text { (2009) }\end{array}$ \\
\hline $\begin{array}{c}\text { Falta de informações suficientes sobre produtos } \\
\text { de empresas socialmente responsáveis }\end{array}$ & $\begin{array}{c}\text { Motta e Rossi (2003); Silva e Bertrand } \\
\text { (2009) }\end{array}$ \\
\hline $\begin{array}{l}\text { O consumidor dá mais valor a itens como preço e } \\
\text { qualidade do que para a RSC }\end{array}$ & Castro et al. (2007) \\
\hline A RSC é um atributo que diferencia a marca & Mrtvi (2003) \\
\hline $\begin{array}{l}\text { Decisão de compra do consumidor é influenciada } \\
\text { pela RSC }\end{array}$ & $\begin{array}{c}\text { Romaniello e Amâncio (2005); Serpa e } \\
\text { Avila (2006a) }\end{array}$ \\
\hline $\begin{array}{l}\text { Consumidores estão dispostos a “punir” as } \\
\text { empresas socialmente irresponsáveis }\end{array}$ & $\begin{array}{l}\text { Romaniello e Amâncio (2005); Serpa e } \\
\text { Fourneau (2007) }\end{array}$ \\
\hline $\begin{array}{l}\text { Consumidores estão dispostos a pagar um preço } \\
\text { um pouco maior por um produto de uma empresa } \\
\text { socialmente responsável }\end{array}$ & Serpa e Avila (2006b) \\
\hline $\begin{array}{l}\text { Consumidores possuem dificuldade em definir } \\
\text { RSC }\end{array}$ & Serpa e Fourneau (2007) \\
\hline $\begin{array}{c}\text { Consumidores têm interesse por informações } \\
\text { sobre a atuação socialmente responsável das } \\
\text { empresas }\end{array}$ & Instituto Ethos (2002) \\
\hline
\end{tabular}

Figura 1: Principais resultados de pesquisas anteriores.

Fonte: Dados da pesquisa bibliográfica.

Como pode ser visto, há pesquisas com resultados diferentes. Enquanto algumas evidenciam que o consumidor ainda não compra produtos de empresas socialmente responsáveis, outras apontam o contrário. No entanto, a maioria dos estudos aponta que o consumidor ainda não leva em conta a RSC no momento de realizar suas compras. Além disso, enquanto há pesquisas que mostram que os consumidores estão dispostos a pagar um preço maior por um produto responsável, 
há outras pesquisas que mostram que o consumidor dá mais valor a itens como preço e qualidade, do que para o atributo da prática da RSC.

Também vale citar um estudo realizado pelo Instituto Ethos (2002) sobre a percepção do consumidor brasileiro em relação à RSC. A Tabela 1, a seguir, foi retirada dessa pesquisa e mostra as respostas dos consumidores sobre a intenção de prestigiar uma empresa socialmente responsável, comprando seu produto. A pesquisa compara os anos 2000, 2001 e 2002.

Tabela 1: Consumidores prestigiam a RSC?

\begin{tabular}{|l|c|c|c|}
\hline PRESTIGIAR & $\mathbf{2 0 0 0}$ & $\mathbf{2 0 0 1}$ & $\mathbf{2 0 0 2}$ \\
\hline Não pensou em fazer isto & $58 \%$ & $71 \%$ & $69 \%$ \\
\hline Pensou em fazer isto, mas acabou não fazendo. & $15 \%$ & $11 \%$ & $14 \%$ \\
\hline Efetivamente fez isto no último ano & $24 \%$ & $16 \%$ & $16 \%$ \\
\hline NS/NR & $3 \%$ & $2 \%$ & $1 \%$ \\
\hline
\end{tabular}

Fonte: Adaptado de Instituto Ethos (2002).

Como pode ser visto na Tabela 1, a maioria dos consumidores não pensou em prestigiar uma empresa socialmente responsável e, se comparar os anos 2000 e 2002, esse número de pessoas aumentou. E, em relação a aqueles que efetivamente prestigiaram uma empresa socialmente responsável, comparando os anos 2000 e 2002, a quantidade de respondentes diminuiu. Isso mostra que a mobilização das pessoas ainda é pequena.

\subsection{A irresponsabilidade social corporativa e a "punição" de empresas}

Existem também, em menor número, pesquisas sobre a irresponsabilidade social das empresas e o ato de "punir" empresas irresponsáveis deixando de comprar seus produtos. Trata-se de uma abordagem relevante, embora ainda pouco explorada (D'Angelo, 2003).

A punição de uma empresa socialmente irresponsável pode ser mais trabalhosa do que o ato de prestigiar as empresas socialmente responsáveis. Deixar de comprar um produto de uma empresa envolvida em um escândalo exige mais esforços do que comprar um produto de uma empresa que pratica a RSC, pois significa excluir a empresa da lista de opções disponíveis e buscar um outro fornecedor (Peixoto, 2003).

Sen, S., Gürhan-Canli e Morwitz (2001) observam que o boicote pode resultar em custos adicionais para os consumidores e que, para tomar a decisão de participar ou não de um boicote a um produto/serviço, o consumidor leva em conta os custos incorridos. Outro aspecto mencionado por esses autores é que, ao decidir se vai boicotar ou não, o consumidor leva em consideração a probabilidade de sucesso do boicote, ou seja, se o fato de ele boicotar vai incorrer em alguma consequência.

Uma pesquisa desenvolvida pelo Instituto Ethos (2002) buscou investigar se os consumidores já pensaram em punir uma empresa socialmente irresponsável, seja por meio do boicote aos seus produtos, deixando de comprá-los, seja pela divulgação negativa da empresa. A Tabela 2, a seguir, mostra as respostas dos consumidores. A pesquisa compara os anos 2000, $2001 \mathrm{e}$ 2002.

Tabela 2: Consumidores punem a irresponsabilidade social?

\begin{tabular}{|l|c|c|c|}
\hline PUNIR & $\mathbf{2 0 0 0}$ & $\mathbf{2 0 0 1}$ & $\mathbf{2 0 0 2}$ \\
\hline Não pensou em fazer isto. & $63 \%$ & $74 \%$ & $67 \%$ \\
\hline Pensou em fazer isto, mas acabou não fazendo. & $16 \%$ & $12 \%$ & $17 \%$ \\
\hline Efetivamente fez isto no último ano. & $19 \%$ & $13 \%$ & $14 \%$ \\
\hline NS/NR & $2 \%$ & $1 \%$ & $2 \%$ \\
\hline
\end{tabular}

Fonte: Adaptado de Instituto Ethos (2002). 
Como pode ser visto na Tabela 2, a maioria dos consumidores não pensou em punir uma empresa socialmente irresponsável e, se comparar os anos 2000 e 2002, esse número de pessoas aumentou. E, em relação a aqueles que efetivamente puniram uma empresa socialmente irresponsável, comparando os anos 2000 e 2002, a quantidade de respondentes diminuiu. Isso mostra que a mobilização das pessoas ainda é pequena, no que tange à "punição" de empresas socialmente irresponsáveis.

Por outro lado, pesquisas realizadas por Romaniello e Amâncio (2005) e Serpa e Fourneau (2007) mostraram que os consumidores estão dispostos a "punir" as empresas socialmente irresponsáveis, deixando de comprar seus produtos. A pesquisa do Instituto Ethos (2002) identificou os comportamentos que mais despertam a intenção de punir entre os consumidores. São eles: veiculação de propaganda enganosa, empresa que causa danos físicos ou morais aos trabalhadores, empresa que vende produtos nocivos à saúde, que polui o meio ambiente, abusa do trabalho infantil e colabora com políticos corruptos.

\section{$2.4 \mathrm{O}$ ceticismo do consumidor}

Outra questão mencionada em algumas pesquisas sobre RSC é o ceticismo por parte dos consumidores, pois não acreditam nas ações socialmente responsáveis das empresas, desconfiando de sua honestidade. Para Szykman, Bloom e Levy (1997), o ceticismo pode afetar a decisão de compra dos consumidores. Trata-se, porém, de um tema a ser aprofundado, especialmente no Brasil, onde há estudos que apontam certa desconfiança dos consumidores em relação às empresas (Chauvel, 2000).

Para Bronn e Vrioni (2001), o indivíduo cético questiona a verdade dos fatos. Segundo esses autores, o nível de ceticismo dos consumidores em relação às ações sociais das empresas é bastante alto. Webb e Mohr (1998) afirmam que o grupo de consumidores céticos é caracterizado pela desconfiança. Eles fizeram uma pesquisa sobre as percepções dos consumidores em relação ao marketing de causas, em que as empresas doam parte da quantia recebida na venda de um produto para alguma causa. Os consumidores céticos demonstraram que não acreditavam plenamente que a empresa doaria o prometido e julgavam que havia um desequilíbrio entre a quantia a ser doada e o ganho financeiro da empresa.

O’Sullivan (1997) aponta que se as empresas não divulgam muito sobre suas ações sociais, os consumidores acreditam que elas estão escondendo algo; já quando elas divulgam muito, os consumidores declaram que as ações sociais estão sendo exploradas pelas empresas. Este é um assunto delicado em termos de marketing, pois é preciso achar o ponto ótimo para se comunicar da forma certa com o consumidor. De acordo com Bronn e Vrioni (2001), muitos consumidores desconfiam dos interesses sociais das empresas. Para Mohr, Eroglu e Ellen (1998), o ceticismo pode ser reduzido à medida que o conhecimento aumenta. Logo, é interessante investigar se existe algum nível de ceticismo nos consumidores em relação às práticas socialmente responsáveis e a motivo do ceticismo, para assim, saber se e como ele poderia ser reduzido.

\section{MÉTODO DE PESQUISA}

De modo geral, os resultados de pesquisa descritos na revisão de literatura apontam, de um lado, que não há consenso quanto às tendências de comportamento dos consumidores em matéria de recompensar empresas socialmente responsáveis ou punir empresas irresponsáveis e, de outro, que outros fatores, como o esforço e os custos envolvidos no comportamento de boicotar, o ceticismo diante do comportamento das empresas e da divulgação de suas práticas parecem exercer uma influência sobre o comportamento dos consumidores em relação às práticas de RSC das empresas. Além disso, várias pesquisas (Motta \&e Rossi, 2003; Castro et al., 2007; Serpa \& Fourneau, 2007; Silva \& Bertrand, 2009) revelam uma atitude positiva no que diz respeito a compra socialmente responsável, que parece não ser colocada em prática pelos consumidores. Diante disso, optou-se,

Revista de Gestão Social e Ambiental - RGSA, São Paulo, v. 5, n. 2, p. 172-186, mai./ago. 2011. 
neste estudo, por uma abordagem qualitativa. Segundo Goldman e McDonald (1987), ao permitir uma interação mais flexível entre pesquisador e pesquisado, entrevistas qualitativas favorecem o surgimento de elementos novos ou imprevistos e a apreensão de aspectos ambíguos ou ambivalentes.

A pesquisa qualitativa é uma "[...]metodologia de pesquisa não-estruturada e exploratória baseada em pequenas amostras, que proporciona insights e compreensão do contexto do problema" (Malhotra, 2001, p. 155). Logo, para esclarecer alguns questionamentos que surgem em decorrência dos diferentes resultados apontados pelas pesquisas quantitativas sobre RSC, optou-se, neste estudo, em se realizar uma pesquisa qualitativa. Assim, foi realizada uma pesquisa de campo para investigar os efeitos das ações de RSC das empresas sobre o comportamento de compra dos consumidores. $\mathrm{O}$ público-alvo compreendeu profissionais de engenharia, que moravam no estado do RJ. Foram entrevistados indivíduos que já estavam estabelecidos no mercado de trabalho e eram responsáveis pelo seu sustento.

A coleta de dados foi feita por meio de entrevistas em profundidade, baseadas em roteiro de entrevista, construído com base em revisão da literatura. O roteiro de entrevistas abordou os seguintes tópicos: visão dos entrevistados sobre o conceito de RSC; importância do tema em sua percepção; se na hora de realizar uma compra já haviam dado preferência a um produto de empresa responsável; se qualidade e preço influenciavam a compra; se a RSC diferencia a marca; se já tinham deixado de comprar de empresa antiética; se a quantidade de informação a respeito de RSC era suficiente; se a informação influenciaria a compra; opinião sobre o que leva as empresas a investirem em RSC; se os entrevistados acreditam na honestidade das empresas ao praticar a RSC; opinião a respeito dos resultados de muitas pesquisas mostrarem que o consumidor brasileiro ainda não faz suas compras levando em consideração a RSC.

As entrevistas foram gravadas e, posteriormente, transcritas para análise. Foram entrevistados dez consumidores, sendo oito mulheres e dois homens. Os entrevistados não foram identificados na pesquisa, sendo citados por siglas. As mulheres foram representadas pelas siglas M1, M2, M3 e assim por diante e os homens foram identificados pelas siglas H1 e H2.

\section{ANÁLISE DOS RESULTADOS}

\subsection{Percepção a respeito da $\mathrm{RSC}$}

A visão dos entrevistados sobre a definição de RSC mostrou heterogeneidade, abordando suas diversas dimensões. Alguns entrevistados destacaram o aspecto social, ou seja, o aspecto da sociedade, do outro, como pode ser visto nos depoimentos (M6 - "Bom, existem vários tipos de RSC. Acho que a RSC é uma obrigação que um deveria ter para com o outro. Isso pode se refletir em termos de uma empresa, o que essa empresa tem em termos de RSC com a sociedade, com os habitantes da localidade ... Então, acho que é isso, essa preocupação de não prejudicar o outro, de ajudar quando pode..."; H1 - "Seria a responsabilidade que nós, como consumidores, como pessoas civis, temos com toda a sociedade, de uma maneira geral, mesmo na compra de um produto, ou você fazendo um trabalho social, formas desse tipo ... você ajudar a sociedade de um modo geral."; H2 - "Responsabilidade social é, como você vive em sociedade, é você cuidar não só da sua vida [...] mas você também precisa colaborar com a vida das outras pessoas [...] então todos devemos ter uma responsabilidade não só consigo, mas também com os demais."). Esses entrevistados veem a RSC como algo voltado para a dimensão social (Enderle \& Tavis, 1998; Mohr et al., 2001; Ashley, 2002) e, aparentemente, somente para esta dimensão, visto que só contemplaram esse aspecto em seus depoimentos.

Já outras informantes mostraram uma visão mais voltada para os atributos ambientais de um produto de uma empresa, isto é, ligaram a RSC à preocupação das empresas com a destinação de seus produtos e as suas consequências para o meio ambiente, que também é uma outra dimensão da RSC (Enderle \& Tavis, 1998; Mohr et al., 2001; Ashley, 2002). Elas também consideraram a 
dimensão social, porém com menor ênfase (M4 - "RSC é pegar um ciclo de empresas que tenham responsabilidade ou que deem importância à questão social, tanto na reciclagem quanto na produção, na destinação final de seu produto etc. Isso seria todo um ciclo de responsabilidade voltada para a sociedade."; M8 - "Não sou especialista nessa área, mas a ideia que eu tenho é que RSC é quando você faz uma atividade, mas sempre com a preocupação de se isso vai causar algum dano futuramente, se vai prejudicar o meio ambiente ou a sociedade em geral.").

Os outros entrevistados tiveram respostas variadas. Uma relatou que a RSC se refere a inserir as pessoas que estão fora do consumo e da realidade do mundo, trazendo-as para essa realidade, ou seja, uma visão social (Enderle \& Tavis, 1998; Mohr et al., 2001; Ashley, 2002; Maignan \& Ferrell, 2004), contudo bastante voltada para o consumo, já que menciona que deve haver uma inclusão social para que as pessoas possam consumir.

Outra entrevistada relatou que a RSC busca atender os consumidores da forma correta vendendo produtos que não ofereçam risco de danos ao consumidor. Logo, foi mencionado um aspecto que é citado por Ashley (2002), quando ela diz que um dos vetores da RSC é a satisfação dos seus clientes e consumidores.

Outra entrevistada relacionou a RSC ao marketing de causas, sugerindo que a RSC é quando o indivíduo compra algo relacionado à criação de um fundo que vai para alguma causa social. Outra entrevistada relacionou a RSC à diminuição do consumismo, numa visão relacionada à dimensão ambiental (Enderle \& Tavis, 1998; Mohr et al., 2001; Ashley, 2002), já que o consumismo pode causar impactos ao ambiente.

Em relação à importância do tema RSC, foi unanimidade que este assunto possui relevância. $\mathrm{E}$ as respostas em relação a essa importância tiveram congruência com as visões de RSC dos informantes. Quem enxerga a RSC como uma forma de incluir a população que está fora do consumo nessa realidade, vê a RSC como importante para reduzir essa exclusão. Quem vê a RSC como uma forma de atender os consumidores da forma correta, ofertando produtos que não sejam danosos aos usuários, percebe sua importância, pois ela pode minimizar os riscos de danos ou prejuízos causados aos consumidores. Aqueles que dizem que a RSC está ligada às consequências ambientais do produto afirmam que ela é importante porque a empresa passa a se preocupar com a cadeia produtiva do produto, reduzindo os impactos ambientais. Além disso, também citam os impactos positivos da redução de trabalho infantil, da garantia do futuro das próximas gerações, da redução da poluição e da favelização, a preocupação com os funcionários e benefícios para a sociedade.

Outros entrevistados ainda acrescentaram em relação a essa questão que deveria haver uma fiscalização em relação às práticas socialmente responsáveis, devido à relevância do assunto, e afirmaram que esse tema precisa ser muito estudado, ainda mais no cenário brasileiro onde há grande desigualdade social.

\subsection{Comportamento de compra e RSC}

Em relação à influência das práticas de RSC no comportamento de compra dos consumidores, a maioria afirmou que não se lembrava de situações em que tivesse levado esse atributo em conta na hora de efetuar uma compra, como pode ser visto nos depoimentos (M1 - "Nunca pensei nisso na hora da compra ... porque não tem um selo, uma marca, de um modo geral, não tem..."; M4 - "Não, não me lembro ... É muito difícil você saber se o produto que você está comprando, ... acho que só após uma divulgação bem mais massificada é que você vai conseguir identificar. Eu acho que eu nunca me atentei, a gente também vive numa vida tão atribulada que você precisa de um produto e ele está ali na sua frente e você não olha nem a marca, você compra e acha que está resolvido o seu problema."; M5 - "Nunca prestei atenção nisso. Acho que se não sendo divulgado, você não presta atenção em que tipo de empresa faz ... A gente acaba vendo o lado do consumidor e não o bem para a sociedade."; M7 - "Infelizmente, não me lembro, não ... Talvez pela pressa, talvez porque a informação não estava muito clara, porque realmente se fosse uma coisa bem evidente, eu

Revista de Gestão Social e Ambiental - RGSA, São Paulo, v. 5, n. 2, p. 172-186, mai./ago. 2011. 
teria percebido...”; M8 - "Não. Nunca pensei nisso porque também nunca me chamaram a atenção para isso."; H1 - "Nunca. Porque talvez eu não conheça as empresas e, normalmente, a gente vai pela qualidade e pelo preço do produto.").

Como pode ser visto, a maioria declarou nunca ter feito uma escolha pautada pelo critério de RSC ou não se lembra de ter feito. Isso corrobora com os resultados de estudos anteriores realizados no país (Instituto Ethos, 2002; Motta \& Rossi, 2003; Castro et al., 2007; Serpa \& Fourneau, 2007; Silva \& Bertrand, 2009). Vale registrar, porém, o tom de pesar de alguns depoimentos ao fazer essa constatação.

Os informantes alegaram que isso ocorreu devido a uma série de motivos, tais como: (a) falta de informação, divulgação; (b) pressa na hora de fazer a compra; (c) não existência de um selo de RSC; (d) compra feita basicamente guiada pelos atributos preço e qualidade. No que diz respeito à falta de informação, algumas pesquisas anteriores mencionaram achados semelhantes (Motta \& Rossi, 2003; Silva \& Bertrand, 2009). No que tange à compra, considerando os atributos preço e qualidade, também há achados sobre este resultado (Castro et al., 2007). Interessante observar a existência da pressa na hora de fazer as compras, mostrando que o consumidor faz compras pensando somente nos produtos, envolvido no seu papel de consumidor. Um relato interessante chama atenção sobre a importância do selo para produtos responsáveis para que, assim, essa questão possa ser lembrada no momento em que se está fazendo a compra.

Por outro lado, houve dois entrevistados que relataram que, ao fazer suas compras, dão preferência às grandes empresas, conhecidas no mercado, pois, de acordo com sua percepção, essas empresas, geralmente, são corretas, possuem certificações como ISO 9000 e ISO 14000. Mesmo assim, um deles mencionou que, infelizmente, na hora em que vai efetuar uma compra, nem sempre é fácil identificar qual a procedência exata do produto e saber se a empresa que o produziu age ou não corretamente.

Em muitos relatos, os consumidores declaram que suas compras são mais guiadas por qualidade. Se fossem comprar um produto de uma empresa socialmente responsável, ele teria que ser de qualidade e, em relação ao preço, a maioria declarou que se ele não fosse muito elevado, eles poderiam comprar de empresas socialmente responsáveis, sim. Esse resultado corrobora com alguns estudos anteriores (Serpa \& Ávila, 2006b; Castro et al., 2007). Os depoimentos podem ser vistos a seguir (H2 - "Olha, todos nós sabemos que na formação dos preços de qualquer produto, não existe mágica, a qualidade tem um preço e essa qualidade te traz benefícios, então eu nunca penso duas vezes sempre que eu tenho um produto que tenha qualidade, eu prefiro esse produto em relação a outro e um dos itens que entra na formação dessa qualidade está sempre ligado à atuação da empresa e, normalmente, atrás dos produtos que reconhecidamente têm qualidade, estão empresas que têm responsabilidade social dentro dos seus parâmetros, dentro dos seus critérios, dentro dos seus valores. E levando isso em conta o preço não é o item número um."; M8 - "Eu sempre valorizo a qualidade, se a qualidade for boa em duas empresas, uma socialmente responsável e outra nem tanto, eu acho que eu vou procurar a socialmente responsável, mesmo com o preço sendo um pouco mais alto, se for exageradamente mais alto, talvez eu comprasse na outra, mas se for um pouco mais alto, nada muito exagerado, e a qualidade fosse a mesma, eu daria preferência pela empresa responsável.").

Por outro lado, alguns entrevistados declararam que o preço também é importante no momento da compra e, por isso, ele não poderia ser superior, caso a empresa fosse socialmente responsável. Isso não está de acordo com pesquisas de autores que mostraram que os consumidores estão dispostos a pagar mais por um produto socialmente responsável (Serpa \& Ávila, 2006b), o que mostra que as respostas são heterogêneas, sendo que há aqueles que estão dispostos e outros que não estão, não havendo então unanimidade (H1 - "Não entraria nesse critério de responsabilidade social, não pagaria por um produto mais caro. Eu acho que isso deve caber ao governo dar algum tipo de isenção nos impostos. Eu pagaria o menor preço se fosse pela mesma qualidade.").

Revista de Gestão Social e Ambiental - RGSA, São Paulo, v. 5, n. 2, p. 172-186, mai./ago. 2011. 
Além disso, há entrevistados que disseram que outros consumidores são capazes de influenciá-los em relação a compras socialmente responsáveis, dizendo que se um consumidor comentar ou indicar um produto, por ser de uma empresa responsável, eles poderiam ser influenciados a comprar determinado produto ou experimentar, mostrando o poder de influência que os outros consumidores podem ter (M3 - "Sim, eu acho que eu tendo a referência da empresa, eu acho que sim, eu olharia com outros olhos, melhores."; H2 - "Bom, é, como a gente vive em sociedade, a gente sempre sofre influência do meio.").

Vários entrevistados ressaltaram que a RSC representa um diferencial para a marca, corroborando resultados de pesquisas anteriores (Mrtvi, 2003) e mostrando que os consumidores podem ter atitudes positivas em relação aos produtos socialmente responsáveis (Motta \& Rossi, 2003; Castro et al., 2007; Serpa \& Fourneau, 2007; Silva \& Bertrand, 2009), apesar de muitos ainda não buscarem comprá-los (Instituto Ethos, 2002; Motta \& Rossi, 2003; Castro et al., 2007; Serpa \& Fourneau, 2007; Silva \& Bertrand, 2009). Os depoimentos a seguir ilustram essa opinião (M3 "Com certeza. Por aquilo que eu já te falei, empresas que não pensam nessa responsabilidade, eu acho que tem tempo de vida curto."; M5 - "Com certeza. Eu acho que em tudo que você faz, se você tem um foco social envolvido, isso te dá maior credibilidade, isso é um diferencial. Só que eu acho que deve haver grandes empresas que trabalham com isso, mas realmente isso não é divulgado, a não ser algum tipo de palestra para as pessoas que trabalham na empresa, mas para o consumidor, para as pessoas que adquirem o serviço, isso não chega."; M6 - "É um diferencial. Porque para mim a RSC está primeiramente atrelada a uma ética, que é uma ética futura, uma ética que o mundo vai ter que ter em determinado momento. E isso vai estar atrelado a uma qualidade..."; M8 - "No meu caso se me comunicassem que aquela marca desenvolve um pensamento de RSC, isso, com certeza, vai me chamar atenção e eu vou procurar realmente consumir mais dessa marca, mas eu preciso que me chamem atenção para isso, porque eu não procuro saber.").

Interessante ressaltar que, por outro lado, uma entrevistada apontou que, em relação a essa questão de a RSC, diferenciar a marca, no início, ela ficava desconfiada da empresa e por isso poderia não representar um diferencial do produto (M7 - "Se eu pensar friamente, sim, mas se for pela emoção, pelo passado, pelas ideias que a gente têm, e são as ideias que a gente tem que movem a gente na hora da compra. No começo, eu ficava desconfiada, porque eu não tinha certeza que aquele produto era realmente de qualidade, ou se eles gastavam dinheiro para ajudar ou para vender. Por exemplo, papel reciclado, num primeiro instante a gente fica desconfiado se aquele papel é limpinho, se sofreu uma filtragem, se foi desinfetado, sei lá de que fonte que ele foi recolhido...”).

\subsection{Comportamento de compra e empresas que não são socialmente responsáveis}

Em relação à situação de deixar de comprar produtos de empresas que não são socialmente responsáveis ou antiéticas, a maioria dos entrevistados relatou que não se lembrava de ter "punido" empresas envolvidas em escândalos corporativos. Entretanto, vários desses entrevistados relataram que isso ocorreu por falta de informação e que eles poderiam deixar de comprar de uma empresa não responsável se tivessem a informação de que ela é uma empresa com práticas incorretas (M7 "Eu não estou me lembrando muito facilmente ... Acho que a informação, às vezes, não é muito clara, se não estiver no invólucro, num produto, também depende do produto..."). Outros disseram que se soubessem que outros consumidores estão deixando de comprar de determinada empresa por motivos éticos, eles fariam o mesmo. Esse resultado confirma pesquisas anteriores que mostram que os consumidores estão dispostos a "punir" empresas irresponsáveis (Romaniello \& Amâncio, 2005; Serpa \& Fourneau, 2007), porém eles ainda não dispõem de tantas informações a respeito de práticas antiéticas de empresas e, com isso, acabam não levando isso em consideração. Esse resultado vai ao encontro dos resultados obtidos na pesquisa do Instituto Ethos (2002), que apontou que a maioria dos consumidores não costuma "punir" as empresas ou já pensou, mas acabou não fazendo.

Revista de Gestão Social e Ambiental - RGSA, São Paulo, v. 5, n. 2, p. 172-186, mai./ago. 2011. 
Já o entrevistado H2 relatou que, apesar de não lembrar de ter deixado de comprar de alguma empresa, procura sempre comprar de empresas conhecidas, que segundo sua percepção, são aquelas que atuam corretamente no mercado e na sociedade. Ele também ratificou que, se percebesse que há indivíduos envolvidos em um boicote a uma empresa, também se veria na situação de deixar de comprar da empresa antiética.

Por outro lado, três entrevistados ressaltaram já ter passado por uma situação de deixar de comprar de determinada empresa, corroborando estudos anteriores de disposição dos consumidores de "punir" empresas irresponsáveis (Romaniello \& Amâncio, 2005; Serpa \& Fourneau, 2007). Os depoimentos ilustram esses boicotes já realizados (M1 - "Já. Material importado da Indonésia, na época que tinha lá a parte de ditadura, coisas desse tipo eu já fiz, sim. Eu acompanhava, a questão da ditadura, a exploração de trabalho infantil também. Empresa que eu sei que faz exploração de trabalho infantil eu não compro."; M4 - "Assim, eu viajei há pouco tempo, e existe uma briga de uma campanha muito grande para que as pessoas não comprem de uma determinada loja lá em Londres, porque ela utiliza o trabalho infantil e quase um trabalho escravizado de pessoas na China, na Índia, e aí eu vi muito isso e lembro que não quis comprar nada nessa loja, por causa de toda essa campanha, porque os ativistas estavam nas ruas falando ..."; M5 - "A própria 'Casa e Vídeo', que é uma empresa muito grande, me lembro que recentemente teve um problema com fiscalização de produtos e você querer saber se o produto tem realmente uma procedência boa e aí eu deixei de comprar, não compro mais nada lá desde então").

Como pode ser percebido, os entrevistados mostraram-se mais inclinados a deixar de comprar de uma empresa irresponsável do que a comprar de uma empresa socialmente responsável. Pode ser interessante pesquisar futuramente, com maior profundidade, se há uma tendência maior a deixar de comprar produtos de empresas irresponsáveis do que a privilegiar as empresas que são socialmente responsáveis e pesquisar se a informação sobre irresponsabilidade social é maior, o que parece ser.

\subsection{Quantidade de informação}

Em relação à quantidade de informação sobre RSC, foi quase unanimidade que não é suficiente. Nove entrevistados disseram que deveria haver mais informação sobre as práticas de RSC, já que estas são insuficientes nos dias de hoje. Isso está de acordo com alguns achados de pesquisas anteriores (Motta \& Rossi, 2003). Algumas entrevistadas apontam que a quantidade de informações é pouca e, por isso, elas nem têm certeza se o que elas pensam que é RSC está correto (M1 - "Não, não são suficientes, nem de responsabilidade nem de irresponsabilidade ..."; M2 - "Eu acho que não. A gente ouve muito pouco falar sobre RSC. Às vezes, eu tenho até dificuldade de saber se o que eu acho que é RSC de fato é."; M3 - "Não, não são suficientes, acho que a população tinha que ter uma conscientização pelos meios de comunicação que alertasse..."; M4 "Não, eu acho que não são suficientes, por isso que a gente até peca muito por ignorância."). Contudo, uma entrevistada tem uma visão diferente dos demais em relação a isso. De acordo com ela, está havendo bastante informação sobre RSC, principalmente em anúncios na televisão. Porém, ela também fez uma crítica a esses anúncios sugerindo que alguns deles procuram enganar os telespectadores (deu como exemplo alguns comerciais de bancos).

Em relação à quantidade de informações disponíveis sobre ações irresponsáveis de empresas, todos os entrevistados disseram que as informações existentes são insuficientes, mas existem de forma escassa. Alguns abordaram, de forma crítica, que muitos escândalos corporativos são abafados e, por isso, acabam não sendo divulgados (M2 - "Acho que não. A gente lê de vez em quando algumas coisas, mas não chega nem aos pés dos escândalos políticos, daquelas coisas que acho que impressionam mais. Ou outro escândalo de uma empresa muito grande que a gente ouve falar ... Se for uma empresa menor não chama muita atenção. A gente lê naquelas notas de jornal quando tem defesa do consumidor, aí é que você vê problemas que nem imaginava que existiam em algumas empresas..."; M4 - "Eu também não sei, muitas empresas conseguem comprar os meios de 
comunicação para que não seja divulgado."; M6 - "Acho pouco também. Às vezes, sai alguma coisa e a gente não tem tempo também de ler, a gente acaba sabendo por outras pessoas ... Por exemplo, o leite, às vezes, acontece: "apareceu alguma coisa no leite”, aí a gente nem compra o leite mais. Mas quando isso é divulgado."; M7 - "Não são suficientes, porque também é uma coisa que eu reparei como pessoa que assiste televisão, que escuta rádio, que só aparece o primeiro escândalo e nunca mais a gente fica sabendo do que foi feito com aquela pessoa, se ela deu o dinheiro de volta ..."; H1 - "Acho que não, acho que isso tudo é muito abafado.").

Todos disseram que poderiam deixar de comprar de empresas irresponsáveis se existisse mais informação disponível, porém três entrevistados fizeram uma ressalva em relação a essa questão. Uma entrevistada disse que hoje ela poderia ser influenciada pela quantidade de informação disponível, pois possui boas condições financeiras, mas, antes, quando ela tinha um salário mais baixo, sua compra era ditada pelo preço. Outra entrevistada ressaltou que se houvesse mais informação sobre escândalos corporativos ela deixaria de comprar da empresa, porém ela ficaria com pena dos funcionários dessa empresa, que correria o risco de fechar, mas mesmo assim ela deixaria de comprar. Um outro entrevistado ressaltou que mesmo ele podendo deixar de comprar da empresa irresponsável, o preço e a qualidade do produto ainda importariam muito.

Alguns entrevistados apontaram sugestões para uma melhor difusão da informação (M4 "Acho que comerciais enfatizando isso, campanhas, informativos até para as escolas mesmo, as empresas irem levar essa informação para as escolas, no produto tem que ter esse esclarecimento. Eu acho que devia ser exigido no supermercado que tivesse sessões, como existe dos orgânicos, hoje você tem os orgânicos e os não-orgânicos, você tem os diets onde tem só artigos dietéticos."; M8 - "Nos meio de comunicação: televisão, jornal, revista, até nos meios de propaganda das empresas."). De acordo com os depoimentos colhidos, essa difusão deveria ser feita nos meios de comunicação em geral, na propaganda da empresa e por meio de selos de RSC, que diferenciem a marca e informem a procedência do produto.

Vale notar o comentário de uma entrevistada que se contrapõe a essa visão. Para ela, a sociedade ainda não tem interesse nesse tipo de informação, ou seja, não há demanda e, por isso, a mídia dá pouco espaço ao assunto. Segundo ela, ainda falta maturidade à sociedade para uma preocupação, de fato, com as práticas socialmente responsáveis; falta vontade de tomar consciência desse tipo de ação e, consequentemente, esclarecimento sobre o tema.

\subsection{Crenças do consumidor: razões para ter RSC e ceticismo}

Os entrevistados relataram suas percepções a respeito das razões que levam as empresas a investirem em programas de RSC. Essas percepções foram bem divididas. Para um grupo, o motivo é financeiro. Segundo esses entrevistados, as práticas de RSC irão trazer benefícios para a empresa. Para alguns, os benefícios são associados ao fato de que os consumidores comprarão seus produtos, aumentando então sua lucratividade; para outros, eles decorrem da legislação fiscal, pois a empresa, ao adotar essas práticas, se beneficia com a isenção de impostos. Um segundo grupo relacionou o investimento em RSC à melhoria na imagem da empresa, alegando que, ao investir nessas práticas, a empresa está melhorando suas qualificações perante a opinião pública. Neste grupo, alguns apontaram que o investimento em RSC é feito para o marketing da empresa, para chamar a atenção das pessoas. Há, finalmente, um quarto grupo, mais otimista, que enxerga os investimentos em ações socialmente responsáveis como algo necessário, como uma resposta que as empresas estão tendo em relação a uma necessidade, tendo a visão de que esse é caminho para o futuro, de que é importante ter práticas corretas.

Quanto à honestidade das empresas em suas campanhas de RSC, a maioria dos entrevistados declarou que depende da empresa; nem sempre eles acreditam, mostrando certo ceticismo em relação à prática de RSC das empresas. Isso confirma o que dizem Bronn e Vrioni (2001) de que o nível de ceticismo dos consumidores em relação às práticas sociais é alto (M2 - "Nem sempre. Porque a gente vê que tem muita coisa que eles falam e não fazem. É como político (risos)."; M3 - 
"Acho que não. Olha, eu não coloco a mão no fogo, eu só coloco a mão no fogo por mim mesma, então não acredito 100\%."; M4 - "Para dizer a verdade, nem sempre, porque tem coisas que você sabe que o empresário está falando para ganhar um público, mas não é o que ele realmente faz. Eu não consigo fazer doação por telefone, por melhor que seja a boa intenção da pessoa em ligar para você pedindo um donativo para uma causa nobre, eu não consigo fazer isso, eu prefiro ir ao local, conhecer o local para fazer a doação..."; M6 - "Depende. Tem empresa que fala, fala e não faz nada, porque tem corrupção. Agora a grande maioria das empresas privadas, quando elas falam, nem tudo é 100\%, mas boa parte, acho que a maioria realmente faz ... acho que elas têm feito alguma coisa, coisas que, na minha época, há trinta anos não tinha nada.").

Como apontam Mohr et al. (1998), o ceticismo pode ser reduzido à medida que o conhecimento aumenta, sendo então interessante disponibilizar mais informações à sociedade sobre as práticas socialmente responsáveis. Contudo, como observa O'Sullivan (1997), é importante a empresa saber equilibrar essa divulgação das informações, pois há o risco dos consumidores acharem que as ações sociais estão sendo exploradas pelas empresas. Transparência e visibilidade parecem ser essenciais nesse sentido.

Por outro lado, uma parcela menor dos entrevistados respondeu que acredita na honestidade das ações de RSC. De acordo com esse grupo de entrevistados, as empresas que se dispõem a realizar práticas socialmente responsáveis são honestas e, de fato, a praticam.

Por fim, como a maioria das pesquisas feitas anteriormente no Brasil revelou resultados que apontaram que os consumidores ainda não levam em conta a RSC das empresas ao fazer suas compras, os entrevistados expressaram suas opiniões em relação às possíveis causas desse fato. A maioria abordou a questão de falta de informação, isto é, como a informação sobre as práticas de RSC é pouco divulgada, os consumidores ficam sem saber e, por isso, não se atentam para esse fato na hora de efetuar a compra.

Outros abordaram a questão da deficiência na educação do povo brasileiro que acaba não despertando essa cultura socialmente responsável (M2 - "Porque eu acho que é uma característica do brasileiro, o nosso povo tem pouca cultura, é um povo um pouco ignorante, as pessoas leem pouco ... na maior parte do Brasil, não tem muito acesso a informação...”).

A entrevistada M2, além de citar a questão cultural do povo brasileiro, adicionou que, por haver essa deficiência, as pessoas acabam comprando pelo preço e pela marca. Alguns entrevistados apontaram essa questão de preço, marca e qualidade no momento da decisão de compra (M3 "Porque eu acho que a maioria da população visa o preço, então a maioria está sempre buscando produtos mais baratos e, além disso, a falta de, como eu falei, a falta de veiculação nos meios de comunicação em relação às informações sobre o tema..."; H1 - "Acho que a pessoa preza muito, sim, a qualidade e o preço. O terceiro fator seria a RSC.").

Outra entrevistada abordou que a sociedade ainda não leva em conta a RSC na hora de realizar suas compras, por causa da pressa, já que dá trabalho procurar saber e pesquisar sobre quais são as empresas socialmente responsáveis. Dessa forma, para superar essa questão, as empresas poderiam disponibilizar mais informação e fazer com que chegue ao consumidor para que ele não precise correr atrás.

Outra entrevistada sugeriu que essa falta de compra socialmente responsável decorre da falta de maturidade da sociedade, por questões de cultura e educação. Ela observou que outras sociedades mais amadurecidas dão mais importância a essa questão.

\section{CONSIDERAÇÕES FINAIS}

Este artigo teve o objetivo de investigar os efeitos da RSC no comportamento do consumidor. Para isso, foram feitas entrevistas em profundidade com dez consumidores que eram profissionais de engenharia.

Houve unanimidade em relação à importância do tema para a sociedade, porém, os resultados obtidos mostraram que os entrevistados possuem visões variadas sobre o que é RSC. Ao

Revista de Gestão Social e Ambiental - RGSA, São Paulo, v. 5, n. 2, p. 172-186, mai./ago. 2011. 
defini-la, predominou a incerteza, com visões bastante diversas do que seja a RSC, de fato. Na verdade, até no meio acadêmico, esse assunto gera controvérsias, havendo a necessidade de um maior aprofundamento e legitimação do conceito. Parece, assim, natural que, mesmo num público com elevado nível de instrução, como o aqui estudado, haja dúvidas a esse respeito. Ou seja, apesar do espaço dado ao tema nos meios de comunicação - revistas, jornais, televisão - parece ser importante haver uma discussão mais profunda e um esclarecimento maior sobre este assunto.

Quanto ao consumo, em geral, os entrevistados não se lembraram de ter buscado em suas compras, dar preferência a empresas socialmente responsáveis e o principal motivo citado foi a falta de informação (os depoimentos mostraram um tom de pesar por não considerar a RSC). Também foram alegados: a pressa, preguiça em buscar a informação, a falta de um selo de RSC e o fato de as compras serem feitas valorizando mais os atributos preço e qualidade. De forma geral, as compras são mais guiadas pela qualidade e, para alguns, o preço também é fundamental. Portanto, os produtos socialmente responsáveis não podem pecar em relação a esses dois atributos. Por outro lado, os entrevistados consideram a RSC um diferencial para a marca, sendo um atributo que pode ser explorado, porém, levando em conta a qualidade e o preço.

Alguns já deixaram de comprar de empresas que tiveram práticas irresponsáveis e antiéticas, o que sugere que os entrevistados possuem maior inclinação a "punir" a empresa do que a "presenteá-la". Vale observar que isso pode estar relacionado à informação. Neste aspecto, é possível que a exposição à informação, em casos de denúncias de comportamento socialmente irresponsável, seja maior do que a que diz respeito aos programas de RSC das empresas. Em relação às informações disponíveis, os entrevistados apontaram que existe pouca informação sobre RSC e irresponsabilidade social.

De modo geral, os consumidores pesquisados são céticos em relação às práticas de RSC, porém há alguns otimistas que acreditam na honestidade das empresas que praticam a RSC. Portanto, parece que informar a sociedade é uma solução razoável para mudar o comportamento do consumidor para que ele comece a ser responsável.

Além disso, os consumidores pesquisados parecem estar sensibilizados à RSC. O que falta para que esta seja levada em consideração na hora de realizar compras é uma informação confiável e de fácil acesso, já que eles não querem 'correr atrás da informação'. Para isso, pode ser feito publicidade e oferecida informação na embalagem do produto. No entanto, seria interessante, se houvesse a criação de um selo padrão de RSC, que fosse de uma origem isenta e confiável, para reduzir o ceticismo do consumidor e fazer com que o consumidor que tem pressa pudesse identificar rapidamente a empresa com RSC.

Algumas sugestões para futuras pesquisas seriam realizar esse estudo em outros grupos de consumidores e estados do Brasil para que houvesse comparações e até realizar comparação entre países. Estudos quantitativos podem ser desenvolvidos a partir dos resultados aqui apresentados. Poderiam, em especial, investigar a questão da comunicação da RSC pelas empresas e o apelo de selos conferidos por instituições reconhecidas pelo público.

\section{REFERÊNCIAS}

Ashley, P. A. (2002). Ética e responsabilidade social nos negócios. São Paulo: Saraiva.

Bronn, P. S., Vrioni, A. B. (2001). Corporate social responsibility and cause-related marketing: an overview. International Journal of Advertising, 20, 207-222.

Carroll, A. B. (1991). The pyramid of corporate social responsibility: toward the moral management of organizational stakeholders. Business Horizons, 39-48.

Revista de Gestão Social e Ambiental - RGSA, São Paulo, v. 5, n. 2, p. 172-186, mai./ago. 2011. 
Castro, F. A. R., Siqueira, J. R. M., Kubrusly, L. S. (2007). A influência da responsabilidade social coorporativa no comportamento do consumidor na cidade do Rio de Janeiro. Anais do ENANPAD, 31, Rio de Janeiro, RJ, Brasil.

Chauvel, M. A. (2000). Consumidores insatisfeitos: uma oportunidade para as empresas. Rio de Janeiro: Mauad.

D’angelo, A. C. (2003). A ética no marketing. Revista de Administração Contemporânea, 7 (4), 55 75.

Enderle, G., Tavis, L. A. (1998). A balanced concept of the firm and the measurement of its longterm planning and performance. Journal of Business Ethics, 17 (11).

Fortanier, F., Kolk, A. (2007). On the economic dimensions of corporate social responsibility: exploring fortune global 250 Reports. Business \& Society, 46 (4).

Goldman, A. E., Mcdonald, S. S. (1987). The group depth interview - Principles and practice. New Jersey: Prentice-Hall.

Instituto Ethos. Responsabilidade social das empresas - Percepção do consumidor brasileiro. Recuperado em 15. out. 2009, de: http://www.ethos.org.br/_Uniethos/Documents/consumidor_200 2.pdf.

Kotler, P., Armstrong, G. (1998). Princípios de marketing. Rio de Janeiro: Prentice-Hall do Brasil.

Maignan, I., Ferrell, O. C. (2004). Corporate social responsibility and marketing: an integrative framework. Journal of the Academy of Marketing Science, 32 (1).

__ ___ Ferrell, L. (2005). A stakeholder model for implementing social responsibility in marketing. European Journal of Marketing, 39 (9/10).

Malhotra, N. K. (2001). Pesquisa de marketing: uma orientação aplicada. (3. ed.) Porto Alegre: Bookman.

Marquis, C., Glynn, M. A., Davis, G. F. (2007). Community isomorphism and corporate social action. Academy of Management Review, 32 (3), 925-945.

Mcwilliams, A.; Siegel, D. (2001). Corporate social responsibility: a theory of the firm perspective. Academy of Management Review, 26 (1), 117-127.

Mohr, L. A., Eroglu, D., Ellen, P. S. (1998). The development and testing of a measure of skepticism toward environmental claims in marketers' communications. The Journal of Consumer Affairs, 32 (1), 30-55.

; Webb, D. J.; Harris, K. E. (2001). Do consumers expect companies to be socially responsible? The impact of corporate social responsibility on buying behavior. Journal of Consumer Affairs, 35 (1), 45-72.

Motta, S. L. S., Rossi, G. B. (2003). A influência do fator ecológico na decisão de compra de bens de conveniência. Revista de Administração da USP, 38 (1), 46-57. 
Mrtvi, V. (2003). O. percepção do consumidor sobre ações corporativas vinculadas ao conceito de responsabilidade social: um estudo no setor de cosméticos. Anais do ENANPAD, 27, Atibaia, Brasil.

O’sullivan, T. (1997). Why charity schemes need a delicate touch. Marketing Week, 20.

Peixoto, M. C. C. (2003). Responsabilidade social e impacto no comportamento do consumidor: um caso da indústria de refrigerantes. Dissertação (Mestrado em Administração de Empresas) Pontifícia Universidade Católica do Rio de Janeiro.

Romaniello, M. M., Amâncio, R. (2005). Gestão estratégica e a responsabilidade social empresarial: um estudo sobre a percepção dos estudantes do curso de administração. Revista Eletrônica de Administração, 11 (3).

Sen, S., Bhattacharya, C. B. (2001). Does doing good always lead to doing better? consumer reactions to corporate social responsibility. Journal of Marketing Research, 38 (2), 225-243.

Sen, S., Gürhan-Canli, Z., Morwitz, V. (2001). Withholding consumption: a social dilemma perspective on consumer boycotts. Journal of Consumer Research, 28 (3), 399-417.

Serpa, D. A. F., Avila, M. G. (2006a). Efeitos da responsabilidade social corporativa no benefício percebido pelo consumidor e na intenção de compra: um estudo experimental. Anais do Encontro de Marketing da ANPAD, 2, Rio de Janeiro, RJ, Brasil.

(2006b). Efeitos da responsabilidade social corporativa na percepção do consumidor sobre preço e valor: um estudo experimental. Anais do ENANPAD, 30, Salvador, Brasil.

., Fourneau, L. F. (2007). Responsabilidade social corporativa: uma investigação sobre a percepção do consumidor. Revista de Administração Contemporânea, 11 (3).

Silva, R. C. M., Bertrand, H. (2009). O comportamento socialmente responsável das empresas influencia a decisão de compra do consumidor? Revista Pensamento Contemporâneo em Administração, 5.

Szykman, L. R., Bloom, P. N., Levy, A. S. (1997). A proposed model of the use of package claims and nutrition labels. Journal of Public Policy \& Marketing, 16 (2).

Ventura, E. C. F. (2003). Responsabilidade social das empresas sob a óptica do "novo espírito do capitalismo". Anais do Enanpad, 27, Atibaia, Brasil.

Vlosky, R. P., Ozanne, L. K., Fontenot, R. J. (1999). A conceptual model of US consumer willingness-to-pay for environmentally certified wood products. Journal of Consumer Marketing, $16(2), 122-136$.

Webb, D. J., Mohr, L. A. (1998). A typology of consumer responses to cause-related marketing: from skeptics to socially concerned. Journal of Public Policy \& Marketing, 17 (2), 226-238.

Data do recebimento do artigo: 24/09/2010

Data do aceite de publicação: 17/07/2011

Revista de Gestão Social e Ambiental - RGSA, São Paulo, v. 5, n. 2, p. 172-186, mai./ago. 2011. 